\title{
La Renuncia al Recurso de Anulación contra el Laudo en el Arbitraje Comercial
}

\author{
Alberto Zuleta Londoño ${ }^{1}$
}

\begin{abstract}
Sumario:
1. Introducción. 2. El marco conceptual. 3. El marco jurídico.3.1 El recurso de anulación y la ley modelo de la CNUDMI. 3.2 El recurso de anulación y la Convención de Nueva York. 3.3 La renuncia al recurso de anulación en el derecho comparado 4. La forma de la renuncia. 5. Consideraciones finales.
\end{abstract}

\section{INTRODUCCIÓN}

Todo laudo puede escapar al control judicial. Basta que las partes se abstengan de utilizar los recursos que les ofrece la ley para impugnarlo, y que cumplan voluntariamente con la decisión del tribunal arbitral. Si esto es así, ¿por qué parecen tan reticentes la comunidad arbitral y las legislaciones aplicables en aceptar que las partes pacten de antemano la exclusión del control judicial, es decir, que lo hagan antes de la expedición del laudo? El presente artículo tiene como contexto esta pregunta y en él se explora el marco conceptual y legal del arbitraje en cuanto a la posibilidad de renuncia del recurso de anulación, o su equivalente.

1. Abogado de la Universidad de los Andes. LL.M. de la Universidad de Harvard (1999). Actualmente trabaja en las áreas de arbitraje y litigio y derecho de la competencia de Cárdenas \& Cárdenas Abogados Lida. en Bogotá. El presente artículo contó con la revisiỏn y comentarios de Daniela Vergel, abogada asociada de Cärdenas \& Cärdenas Abogados Ltda. 
Este debate, sobre si debe ser renunciable o no el recurso de anulación contra un laudo, tiene como trasfondo la noción misma de arbitraje como mecanismo de solución de conflictos. La pregunta lleva implícita la compleja controversia sobre si es concebible un laudo sin control judicial de alguna clase. Los posibles escenarios legales frente a este problema son muchos. En un extremo se encuentra la situación en la que el laudo está sujeto a un recurso de anulación ante un tribunal de la sede del arbitraje (o un tribunal del país conforme a cuya ley se dictó el laudo)2, el cual es irrenunciable por las partes. En este caso, el laudo tiene control judicial en la sede y, además, tendría un segundo control en el lugar de ejecución (cuando éste sea diferente de la sede), normalmente bajo los parámetros previstos en la Convención sobre el reconocimiento y ejecución de las sentencias arbitrales extranjeras, adoptada por la Conferencia de las Naciones Unidas sobre el Arbitramento Comercial, el 10 de junio de 1958 (la "Convención de Nueva York"). En el otro extremo estaría la situación en la que el laudo carece de control judicial. Es decir, sería ejecutable sin control por parte de juez alguno, sea en sede de anulación, de reconocimiento o de ejecución.

A continuación se estudiarán (i) El marco conceptual; (ii) el marco jurídico; (iii) la forma de la renuncia; y (iv) se harán las consideraciones finales del artículo.

\section{El MARCO CONCEPTUAL}

El arbitraje se debate constantemente entre la visión de quienes encuentran en él una figura típicamente contractual y aque-

2. Si bien la explicación del alcance de esta aclaración excede los propósitos del presente articulo, ella obedece a la förmula prevista en el articulo V, numeral $l^{\circ}$ ", literal e) de la Convención de Nueva York:

"1. Sólo se podrá denegar el reconocimiento y la cjecución de la sentencia, a instancia de la parte contra la cual es invocada, si esta parte prueba ante la autoridad competente del pais en que se pide el reconocimiento y la cjecución:

(...)

"e) Que la sentencia no es aún obligatoria para las partes o ha sido anulada o suspendida por una autoridad competente del pais en que, e conforme a cuya ley, ha sido dictada esa sentencia." (Subrayas fuera del texto original). 
llos que piensan que es, en esencia, una forma un tanto más flexible de proceso judicial. A pesar de la existencia de estas vertientes relativamente definidas en cuanto a visiones de lo que es el arbitraje comercial, lo cierto es que en la mayoría de legislaciones arbitrales y las instituciones jurídicas que nacen de ellas se encuentran rastros de uno y otro enfoque.

Una de las áreas de estudio del arbitraje que recibe mayor influencia de esta división conceptual es la que genéricamente puede llamarse el control judicial sobre el laudo, el cual comprende el control en la sede y el control que se ejerce en el foro de ejecución. Una visión predominantemente contractualista del arbitraje probablemente permitiría abogar por mecanismos de control judicial que sean relativamente frugales, análogos a los que se ejercen sobre un contrato firmado por dos (o más) partes. Una visión judicial del arbitraje, por su parte, probablemente nos llevaría hacia el extremo de un control más riguroso, como el que se ejerce sobre un fallo judicial. A continuación se hará un examen del marco jurídico que rodea el asunto, para después entrar en el análisis del mismo.

\section{El marco jurídico}

El arbitraje comercial como disciplina se nutre de una cantidad enorme de fuentes de derecho, pues se trata de la interacción de muchas leyes nacionales entre sí, más que de un marco internacional propiamente dicho, salvo por algunos aspectos puntuales en los que intervienen tratados internacionales. Estas fuentes, a su vez, pueden combinarse en una infinidad de maneras. Por esa razón, para efectos de estudiar lo que sería el marco jurídico del control judicial del laudo, se tomarán las fuentes más importantes que, discutiblemente, son las siguientes: (i) la ley modelo de arbitraje de la CNUDMI. Si bien no es una fuente de derecho, sí reúne muchas de las tendencias conceptuales sobre la materia $y$, además, ha servido de modelo o guía para 
muchas de las legislaciones arbitrales del mundo; (ii) la Convención de Nueva York. Aunque se trate de una norma dictada para regular el reconocimiento de laudos extranjeros, contiene disposiciones relevantes respecto del efecto que tiene la anulación de un laudo para su posterior ejecución; (iii) las legislaciones arbitrales más importantes entre las que permiten, total o parcialmente, la renuncia al recurso de anulación o se establecen excepciones a la procedencia del mismo.

\subsection{El recurso de anulación y la ley modelo de la CNUDMI}

La ley modelo de la CNUDMI establece en el artículo 34 que la petición de nulidad es el único recurso contra el laudo. En él no se dice si sería renunciable por las partes, sino que se establecen las causales que pueden servir para anularlo3.

3. Articulo 34. La peticion de nulidad como único recurso contra un laudo arbitral

“1) Contra un laudo arbitral sólo podrá recurrirse ante un tribunal mediante una peticiòn de nulidad conforme a los párrafos 2) y 3) del presente articulo.

“2) El laudo arbitral sólo podrí ser anulado por el tribunal indicado tn cl articulo 6 cuando:

"a) la parte que interpone la petición prucbe:

"i) que una de las partes en el acuerdo de arbitraje a que se refiere el articulo 7 cstaba afectada por alguna incapacidad, o que dicho acuerdo no es válido en virtud de la ley a que las partes lo han sometido, o si nada se hubiera indicado a este respecto, en virtud de la ley de este Estado; o

“ii) que no ha sido debidamente notificada de la designación de un árbitro o de las actuaciones arbitrales o no ha podido, por cualquier otra razón, hacer valer sus derechos; o

“iii) que el laudo se refiere a una controversia no prevista en el acucrdo de arbitraje o contiene decisiones que exceden los términos del acuerdo de arbitraje; no obstante, si las disposiciones del laudo que se reficren a las cuestiones sometidas al arbitraje pueden separarse de las que no lo estin, sólo se podrain anular estas últimas; 0

"iv) que la composición del tribuna! arbitral o el procedimiento arbitra! no se han ajustado al acuerdo entre las partes, salvo que dicho acuerdo estuviera en conflicto con una disposición de esta Ley de la que las partes no pudieran apartarse o, a falta de dicho acuerdo, que no se han ajustado a csta Ley; o

“b) el tribunal comprucbe:

“i) que, según la ley de este Estado, el objeto de la controversia no es susceptible de arbitraje; o

“ii) que el laudo es contrario al orden público de este Estado.

3) La petición de nulidad no podrá formularse después de transcurridos tres meses contados desde la fecha de la recepción del laudo o, si la petición se ha hecho con arreglo al articulo 33, desde la fecha en que esa petición haya sido resuelta por el tribunal arbitral.

"4) El tribunal, cuando se le solicite la anulación de un laudo, podri suspender las actuaciones de nulidad, cuando corresponda y cuando asi lo solicite una de las partes, por un plazo que determine a fin de dar al tribunal arbitral la oportunidad de reanudar las actuaciones arbitrales o de adoptar cualquier otra medida que a juicio del tribunal arbitral climine los motivos para la petición de nulidad. 
Lo más significativo de las causales de anulación previstas en la ley modelo de CNUDMI es que ellas son de naturaleza procedimental, lo cual podría hacerlas ver como poco importantes en una visión prima facie del tema. Sin embargo, se trata de causales que están destinadas a (i) asegurarque el mecanismo escogido por las partes en el pacto arbitral es el que efectivamente fue utilizado; y (ii) que no se hayan violado normas o conceptos de obligatoria observancia en materia de arbitrabilidad y orden público internacional.

La naturaleza de las causales de anulación previstas en la ley modelo de la CNUDMI, cuya orientación es seguida por muchas legislaciones arbitrales del mundo (aunque no necesariamente lo son las causales específicamente consideradas), hacen que resulte problemático permitir a las partes renunciar a ellas. Como se dijo, son causales cuyo propósito último no es revisar la decisión de fondo sino asegurarse de que el laudo se haya dictado de la manera escogida por las partes en el pacto arbitral y respetando las normas a las cuales estaba sometido en materia de arbitrabilidad y orden público internacional. Por esa razón, la renuncia de antemano al recurso de anulación puede parecer problemática. Se trataría de una especie de carta blanca para que el tribunal incurra en cualquier error $o$, en un caso extremo, cometa alguna arbitrariedad. Esta dificultad puede extenderse a la mayoría de legislaciones del mundo conforme a las cuales ha de resolverse un recurso de anulación pues, como se estableció anteriormente, la orientación del recurso de anulación contenida en la ley modelo de la CNUDMI es seguida en muchos países del mundo.

\subsection{El recurso de anulación y la Convención de Nueva York}

La Convención de Nueva York se ocupa principalmente de los efectos del pacto arbitral y de las condiciones de ejecución de los laudos extranjeros. No establece obligación alguna a cargo de los miembros adherentes respecto de las condiciones en que 
debe surtirse la impugnación de un laudo por los tribunales competentes. Tampoco habla de cuándo puede o no renunciarse el recurso de anulación. Sin embargo, se hacen varias referencias al escenario de la nulidad de un laudo, todas ellas en el contexto de la ejecución del mismo como laudo extranjero.

La primera mención que se hace del recurso de anulación en la Convención de Nueva York es la que aparece en el artículo V, 1.e):

“1. Sólo se podrá denegar el reconocimiento y la ejecución de la sentencia, a instancia de la parte contra la cual es invocada, si esta parte prueba ante la autoridad competente del país en que se pide el reconocimiento y la ejecución:

(...)

“e) Que la sentencia no es aún obligatoria para las partes o ha sido anulada o suspendida por una autoridad competente del pais en que, o conforme a cuya ley, ha sido dictada esa sentencia."

La Convención de Nueva York entiende que cualquier sede puede tener procedimientos internos de control judicial del laudo que conduzcan a su posible suspensión o anulación. En esta norma se establece un mecanismo de respeto por dichas disposiciones, el cual consiste en permitir que se detenga o evite la ejecución de un laudo en el extranjero que haya sido anulado o suspendido por los tribunales de la sede (o los que funjan como tales, según el caso). Si bien existe una doctrina relativamente desarrollada sobre cuáles son los eventos en los cuales se puede ejecutar un laudo que ha sido anulado en la sede (la cual forma parte, de acuerdo con algunos doctrinantes, de la llamada deslocalización del arbitraje comercial internacional), lo cierto es que la inclusión en la Convención de Nueva York de la anulación del laudo como causal para impedir el reconocimiento del mismo en el extranjero es indicativo de que esta posibilidad es un asunto que no se entiende como de interés exclusivo de las partes. Se trata de una disposición legal análoga a la que se podría soste- 
ner respecto de la ejecutoria de una sentencia judicial extranjera, por ejemplo. Esta afirmación resulta parcialmente matizada si se tiene en cuenta que esta causal para evitar la ejecución de laudo solamente opera a solicitud de parte, lo cual puede resultar en que, de facto, se ejecuten laudos anulados en la sede cuando las partes interesadas se abstengan de alegar la anulación del laudo como impedimento para su reconocimiento y ejecución. Sin embargo, sigue siendo cierta.

Por otra parte, el artículo VI de la Convención de Nueva York también merece atención en este contexto:

"Si se ha pedido a la autoridad competente prevista en el artículo V, párrafo 1 e), la anulación o la suspensión de la sentencia, la autoridad ante la cual se invoca dicha sentencia podrá, si lo considera procedente, aplazar la decisión sobre la ejecución de la sentencia y, a instancia de la parte que pida la ejecución, podrá también ordenar a la otra parte que dé garantías apropiadas."

Esta norma establece condiciones especiales para la ejecución de la sentencia cuando el resultado de un posible proceso de anulación aún es incierto. La Convención de Nueva York trata así de balancear el interés de la parte vencedora en una pronta ejecución del laudo, con el respeto debido al control judicial que se ejerce en la sede.

Las dos normas citadas demuestran que, como se dijo anteriormente, la anulación de un laudo por los jueces de la sede (o quienes cumplan la función de los mismos) es un asunto que trasciende el puro interés de las partes. Existe un marco jurídico internacional, previsto en la Convención de Nueva York, diseñado para que, en determinadas circunstancias, los mecanismos de control de la sede sean respetados en el extranjero. 


\subsection{La renuncia al recurso de anulación en el derecho com- parado}

A continuación se describen los regímenes arbitrales más importantes en los cuales se ha excluido el recurso de anulación en ciertos casos, o se les ha permitido a las partes pactar la renuncia del mismo.

\subsection{Bélgica}

La ley belga (ley del 27 de marzo de 1985, que incluyó un nuevo parágrafo 4 al artículo 1717 del Código Judicial) establecía que los tribunales de Bélgica únicamente podrían decidir recursos de anulación de laudos proferidos en ese país cuando por lo menos una de las partes de la disputa era un individuo con nacionalidad o residencia belga, o cuando se tratara de una entidad constituida en Bélgica o con una subsidiaria u otro establecimiento en Bélgica ${ }^{4}$. Esta disposición no preveía una posibilidad de renuncia al recurso de anulación sino que, simplemente, excluía de la posibilidad de este recurso ante los tribunales belgas, a cualquier laudo originado en una disputa que no incluyera a una parte que tuviera con Bélgica un vínculo suficiente, el cual se establecía de acuerdo con los criterios señalados en la norma.

Esta medida fue repensada y luego modificada en 1998, para establecer una regla según la cual era posible para las partes de un acuerdo de arbitraje en un escrito posterior, pactar la renuncia al recurso de anulación cuando ninguna de ellas es una persona natural nacional o residente en Bélgica o una persona jurídica con su asiento principal o una sucursal en Bélgica5. Este cambio tuvo dos consecuencias fundamentales: (i) le devolvió a los tribunales belgas la jurisdicción para conocer del recurso de

\footnotetext{
4. GaillarD, Emmanucl. Tcoria Juridica del Arbitraje Intemacional. $I^{2}$ edición. CEDEP y Thomson Reuters, 2010 para 66-67.

5. Ley de mayo 19 de 1998 que modifić el parigrafo 4 al articulo 1717 del Código Judicial.
} 
anulación que se interpusiera contra cualquier laudo dictado en Bélgica, aún si esa era la única conexión que tenía Bélgica con el arbitraje; y (ii) permitió que fueran las partes de la disputa quienes decidieran, en ciertos casos, si procede o no el recurso de anulación en contra del laudo proferido en territorio belga. Los tribunales belgas, entonces, están ahora facultados para resolver un recurso de anulación interpuesto contra un laudo dictado por un tribunal cuyo único vínculo con Bélgica es que ese fue el lugar de la sede del arbitraje. Estos laudos, sin embargo, están sujetos a control judicial para su ejecución en Bélgica, de acuerdo con el artículo 1710 del Código Judicial Belga ${ }^{6}$.

\subsection{Suiza}

Suiza adoptó la medida en esta materia dos años después de la ley belga de 1985 referida anteriormente y, aunque siguió la línea de establecer la exclusión del recurso de anulación para los laudos proferidos por tribunales cuyo único vínculo con Suiza era el lugar de la sede del arbitraje, lo hizo de manera opcional, como ocurrió en Bélgica posteriormente, en 1998, según se explicó anteriormente. El artículo 192 del estatuto federal de derecho internacional privado de 1987 permitió que las partes de un arbitraje renunciaran total o parcialmente al recurso de anulación, cuando ninguna de ellas tiene su domicilio, residencia habitual o establecimiento comercial en Suiza. Si bien los casos puntuales en los que se puede renunciar al recurso de anulación son distintos con los que se incluyeron en la ley belga de 1998, la filosofía que los inspira parece ser la misma, que es la de tratar como extranjeros, cuando las partes así lo quieran, los laudos cuyo único vínculo con el país es que las partes lo hayan escogido como sede. La ley Suiza exige que el laudo que por esa vía resulte excluido de control judicial de anulación, se trate como un laudo extranjero y, por lo tanto, si se requiere su ejecución en

6. Poudret, Jean François y Sébasticn Besson. Comparative Law of International Arbitration. Second edition, 2007, London: Swect \& Maxwell Ltd.p. 785. 
Suiza, es necesario que se surta previamente un proceso de reconocimiento a la luz de la Convención de Nueva York?

\subsection{Suecia}

En Suecia la posibilidad de excluir ciertos laudos del recurso de anulación tiene su origen, según un sector de la doctrina ${ }^{8}$, en el razonamiento utilizado por la Corte Suprema sueca en el caso "Uganda", fallado en 1989, en el que se estableció que las

partes de un arbitraje que no tuvieran relación alguna con Suecia, podían renunciar al recurso de anulación (sin especificar si la renuncia podía ser parcial o total). La ley sueca de arbitraje de 1999 luego dispuso, en el artículo 51, que si ninguna de las partes en una disputa comercial tiene su domicilio o establecimiento de negocios en Suecia, pueden excluir todas o algunas de las causales de anulación previstas en la ley, con excepción de las de invalidez, las cuales se consideran de orden público y no pueden ser renunciadas.

$\mathrm{Al}$ igual que en el caso suizo, la ley sueca de arbitraje (artículo 51) establece que un laudo respecto del cual se ha realizado una renuncia de este estilo, debe tratarse como un laudo extranjero para efectos de su ejecución en Suecia. Por lo tanto, para este efecto, sería necesario un proceso de reconocimiento previo.

\subsection{Francia}

La reciente ley francesa de arbitraje ${ }^{9}$ trata el tema de forma novedosa, en el sentido que permite que las partes renuncien al derecho de interponer un recurso de anulación contra el laudo

7. Geisinger, Ellion y Vivian Frossarc. Inkmational Arbitration in Switzerland: A Handbook for Practitioners Capitulo 8 - Challenge and Revision of the Award en Gabriclle Kaufmann-Kohler y BlaiscStucki, (Kluwer Law International 2004) pp. 135 - 166.

8. HoBtR. Kaj. Intemational Commercial arbitration in Sweden. 1st edition.Oxford University Press. New York, 2011, p. 344.

9. Expedida por el Decreto $2011-48$ del 13 de enero de 2011. Entró en vigencia el J" de mayo de 2011. 
sin establecer condicionamientos de nacionalidad, domicilio u otros similares. Este derecho, sin embargo, no se extiende a la orden de ejecución (I'ordonnaced'exequatur) ${ }^{10}$, la cual nunca puede renunciarse. Esto significa que, al igual que en los casos sueco y suizo, la renuncia al recurso de anulación no implica la posibilidad de ejecución del laudo en Francia sin control judicial alguno, sino simplemente la ausencia del control propio del juez de la sede. El control que le corresponde al juez del lugar de ejecución se ejerce plenamente.

\subsection{Estados Unidos}

El Federal Arbitration Act de los Estados Unidos de América no contempla la posibilidad de renuncia al recurso de anulación. Sin embargo, en varias ocasiones se ha intentado alegar ante cortes estadounidenses que las partes renunciaron válidamente a dicho control al acogerse a un reglamento que dice que el laudo será final, por ejemplo. Los casos conocidos en esa materia han tenido como resultado la decisión de las cortes en el sentido de establecer que dichas estipulaciones son ineficaces al pretender suprimir la competencia de las cortes americanas para resolver el recurso de anulación bajo el FAA.11

\subsection{Panamá}

El caso panameño es muy interesante porque existe un pronunciamiento constitucional específico sobre el tema. Frente a la constitucionalidad del artículo 36 del decreto-Ley No. 5, que establecía que el recurso de anulación se podía renunciar por las partes o se podía establecer por el reglamento de arbitraje apli-

10. atcl.lnh, Ana. WAde, Shai. Tetley, Andrew. TAOK, Mireille. France revises arbitration law. Reed Smith Client alerts, May 25, 2011.

http://www,reedsmith.com/publications/search_publications.cfm? widCall l =customWidgets.content_view_1\&cit_id=31305

11. BORN, Gary. International Commercial Arbitration: Cases and Matcrials-Chapter 15: Annulment and Revision of Intemational Arbitral Awards. Klawer Law International 2011 pp. 1047-1123. 
cable, la Corte Suprema de Justicia señaló que "una norma con jerarquín legal que permitn a las partes renunciar anticipadamente y en abstracto al ejercicio de un medio de impugnación es contraria a la garantía fundamental del debido proceso ${ }^{12}$."

Este pronunciamiento resulta interesante porque se refiere a la renuncia "anticipada" y "en abstracto" al ejercicio del recurso. Esto significa que quien quiera renunciar a ejercer el derecho a impugnar un laudo debe saber exactamente cuál es la falencia frente a la cual está ejerciendo esa renuncia, lo cual únicamente es posible cuando el laudo ya ha sido expedido. Es la renuncia anticipada la que resultó inconstitucional. Esto guarda coherencia con lo dicho al principio del presente artículo en el sentido de que todo laudo puede de facto escapar al control judicial. La discusión es, finalmente, si dicho control se puede renunciar por las partes antes de conocer el alcance exacto de la renuncia, por no haberse proferido aún el laudo.

\subsection{Perú}

El Decreto Legislativo No. 1.071, el cual rige en el Perú desde el $1^{\circ}$ de septiembre de 2008, permite en el artículo 63, que las partes de un acuerdo arbitral renuncien expresamente al recurso de anulación si ninguna de ellas es de nacionalidad peruana o tiene su domicilio, residencia habitual o lugar de actividades principales en el Perú.

"Artículo 63

\section{(...)}

"8. Cuando ninguna de las partes en el arbitraje sea de nacionalidad peruana o tenga su domicilio, residencia habitual o lugar de actividades principales en territorio peruano, se podrá acordar expresamente la renuncia al recurso de

12. Citado por Jısı́nez, Dyala. "Renuncia al recurso de anulación: alcances y análisis comparativo." En El Arbitraje en el Perú y el Mundo, Tomo I Instituto Peruano de Arbitraje, 2008, pp. 531-538. 
anulación o la limitación de dicho recurso a una o más causales establecidas en este artículo. Si las partes han hecho renuncia al recurso de anulación y el laudo se pretende ejecutar en territorio peruano, será de aplicación lo previsto en el título VIII."

El título VIII mencionado en este artículo se refiere al reconocimiento y ejecución de laudos extranjeros. Esto significa que en el caso peruano la renuncia al recurso de anulación también conduce a que se trate el laudo como extranjero y, como se desprende del aparte subrayado, la ejecución del mismo en el Perú requiere del control propio de la sede de reconocimiento.

\subsection{Colombia}

La justicia colombiana se ha referido al tema en una ocasión. La Sala Civil del Tribunal Superior de Distrito Judicial de Bogotá estudió un recurso de anulación interpuesto en contra de un laudo dictado de conformidad con el Reglamento del Centro Internacional de Resolución de Disputas (ICDR por sus siglas en inglés). El tribunal arbitral aplicó, según el acuerdo de las partes, la ley sustancial colombiana y sesionó en la ciudad de Bogotá.

Inicialmente el Tribunal Superior de Distrito Judicial de Bogotá, por vía de la magistrada ponente, declaró inadmisible el recurso por considerar que el Reglamento ICDR, al cual las partes se sometieron expresamente, establecía que un laudo proferido conforme a dicho reglamento era definitivo y, por lo tanto, al escoger ese reglamento para regir el trámite arbitral, las partes habían renunciado al recurso de anulación. Frente al raciocinio de la providencia inicial sobre la imposibilidad de las partes de presentar el recurso de anulación por lo dispuesto en el Reglamento ICDR y el laudo en cuestión, el mismo Tribunal, esta vez en sala dual, manifestó lo siguiente:

“(...) si bien las partes gozan de autonomía para reglamentar el procedimiento, no pueden ir en contra del debido pro- 
ceso a fin de revisar si el procedimiento previsto por las partes fue cumplido o no, en consecuencia el recurso era procedente."

Concluye el tribunal entonces que el recurso es procedente aún si las partes hubieran renunciado a él, por cuanto es un mecanismo tendiente a establecer si el trámite pactado por las partes efectivamente se cumplió. Entendió entonces el tribunal que el recurso de anulación contra el laudo arbitral era irrenunciable a la luz de la ley colombiana ${ }^{13}$. Esto es apenas razonable teniendo en cuenta que la posibilidad de renuncia al recurso de anulación en una legislación traería consigo la falta absoluta de control judicial del laudo, pues la ley colombiana no reemplazaría este recurso con el procedimiento de reconocimiento propio de un laudo extranjero, como sí lo hacen las legislaciones suiza y sueca.

Finalmente, hay que señalar que el proyecto de ley de arbitraje internacional que cursa actualmente en el Congreso colombiano contempla en el artículo 108 la posibilidad de las partes de renunciar al recurso de anulación, siempre y cuando ninguna de ellas tenga su domicilio o residencia en Colombia y, al igual que en las legislaciones suiza y sueca, le otorga a dicho laudo el tratamiento de laudo extranjero el cual deberá ser objeto de control judicial para la ejecución del mismo en Colombia. ${ }^{14}$

\section{LA FORMA DE LA RENUNCIA}

¿Cuándo se entiende que una parte ha renunciado al recurso de anulación? Esta es una pregunta cuya respuesta es comple-

13. Tribunal Superior de Distrito Judicial de Bogota. Sala Dual Civil de Decisión. Auto del 21 de mayo de 2010. Magistrado Ponente: Álvaro Fernando Garcia Restrepo.

14. Proyecto de Ley "Por medio de la cual se expide el Estatuto de Arbitraje Nacional e Internacional y se dictan otras disposiciones": "Articulo 111. Reconocimiento y cjecución. Los laudos arbitrales se reconocerán y cjecutarản asi:

(...)

"3. Los laudos dictados en arbitrajes internacionales cuya sede sea Colombia se considerarán laudos nacionales $y$, por ende, no estarán sujetos al procedimiento de reconocimiento y podrán ser ejecutados directamente sin neesidad de este, salvo cuando se haya renunciado nl recurso de anulación, caso en el cual será necesario su reconocimiento." 
ja. Y lo es porque, además de la renuncia expresa e indiscutible, hecha por las partes en un documento (el que contiene el pacto arbitral $\mathrm{u}$ otro) en términos inequívocos, existe la posibilidad de que exista una renuncia indirecta o tácita. Esta última puede producirse de muchas maneras pero, en particular, por la referencia que hagan las partes en el pacto arbitral a un reglamento de arbitraje que contenga una disposición que sugiera, o señale expresamente, que el laudo carecerá de recursos ${ }^{15}$.

Vale la pena entonces revisar qué se ha dicho en diversos foros respecto de cuándo se entiende que las partes han renunciado a interponer el recurso de anulación. En esta materia los tribunales estatales parecen haber sido supremamente cautelosos.

15. Camara de Comercio Internacional - CCl. Reglamento de Arbitraje ( $1^{\prime \prime}$ de enero de 1998 - 31 de diciembre de 2011).

"Articulo 28. Notificación, depósito y carácter ejecutorio del Laudo.

(...)

6. Todo Laudo es obligatorio para las partes. Al sameter su controversia a arbitraje segun el Reglamento, las partes se obligan a cumplir sin demora cualquier Laudo que se dicte y se considerari que han renunciado a cualesquiera vias de recurso a las que puedan renunciar válidamente."

- Reglamento de Arbitraje ( $I^{*}$ de encro de 2012)

"Articulo 34. Notificación, depósito y carácter ejecutorio del Laudo.

(...)

Todo laudo es obligatorio para las partes. Al someter su controversia a arbitraje según el Reglamento, las paries se obligan a cumplir sin demora cualquier laudo que se dicte y se considerara que han renunciado a cualesquicra vias de recurso a las que puedan renunciar válidamente."

Comisión Interamericana de Arbitraje Comercial- CIAC. Reglamento de Procedimientos (I"Abril de 2002). “Articulo 29. Forma y efecto del Laudo. (...) 2. E1 laudo se dictara por escrito y será definitivo, inapelable y obligatorio para las partes. Las partes se comprometen a cumplir el laudo sin demora."

Centro Internacional para la Resolución de Disputas - ICDR.Reglamento de Arbitraje ( $I^{\mathrm{a}}$ de junio de 2010). "Articulo 27. Forma y Efecto del Laudo. I. El tribunal dictara su laudo prontamente y por escrito. El laudo será definitivo y obligatorio para las partes. Las partes se comprometen a cumplir el laudo sin demora."

Cone de Arbitraje Internacional de Londres - LCIA. Reglatnento de Arbitraje (I" de encro de 1998), Articulo 26. EI Laudo. (...). 26.9. Todos los laudos scrin definitivos y vinculantes para las partes. Las partes, sometiéndose a arbitraje bajo los auspictos de esic Reglamento, se comprometen a cjecutar inmediatamente y sin demora cualquier laudo (condicionado sólo por el Artículo 27). Las partes renuncian irrevocablemente a cualesquicra vias de recurso de apelación o revisión ante cualquier juzgado o autoridad judicial competente, siempre que dicha renuncia puede ser válidamente realizada." 
En Suecia, por ejemplo, el artículo 51 de la ley de arbitraje exige que la renuncia sea escrita y que en ella se diga específicamente que las partes renuncian total o parcialmente al recurso de anulación. Esto significa que la sola referencia a un reglamento arbitral que contenga una disposición que establezca o sugiera la renuncia de las partes al derecho que tiene a impugnar el laudo, es insuficiente para entender que este derecho ha sido renunciado ${ }^{16}$. Lo mismo ocurre con el artículo 1522 del Código de Procedimiento Civil Francés, el cual permite la exclusión del recurso de anulación cuando las partes "expresamente" renuncien a él. La inclusión del término "expresamente" probablemente pretende evitar la discusión sobre lo que ocurriría con las renuncias tácitas o aquellas que se producen con ocasión de la referencia a un reglamento de arbitraje.

Las cortes de los Estados Unidos de América, por su parte, han tenido una aproximación similar al tema. Varios tribunales han interpretado las referencias hechas a un reglamento arbitral como insuficientes para concluir que en ellas se tuvo el propósito de renunciar al recurso de anulación contra el laudo ${ }^{17}$.

En el Perú la ley general de arbitraje exige que la renuncia sea expresa y escrita. No se admite como renuncia la simple referencia a un reglamento de arbitraje.

La regla, entonces, parece ser que la renuncia al recurso de anulación, cuando ella es posible, debe ser expresa y escrita. No pareciera haber casos en los que la simple referencia a un reglamento de arbitraje bastara como renuncia al recurso de anulación.

16. HOnÉr, Op. cit. p. 344.

17. Born, Gary. Op Cit. pp. 1047-1123.

260 Revista Ecuntoriana de Arbitraje: 


\section{CONSIDERACIONES FINALES}

Los diferentes escenarios planteados a lo largo del presenteartículo permiten concluir que, como regla general, la posibilidad de que las partes renuncien al recurso de anulación no se ha extendido a la ausencia absoluta de control judicial sobre el laudo. Los países que permiten o han permitido en algunos momentos de su historia que las partes renuncien al recurso de anulación, o que han establecido excepciones a la procedencia del mismo en ciertas circunstancias, han reservado siempre la posibilidad de control judicial en el momento de ejecución. Si bien este es un mecanismo que desmejora la posibilidad de control para las partes, especialmente para la parte demandante vencida, quien no tendrá un foro de ejecución ante el cual plantear la irregularidad que encuentre en el laudo, sí es indicativo de que estamos lejos de los laudos que carecen absolutamente de control.

Como se dijo al principio del presente artículo esto podría parecer, prima facie, contradictorio con el hecho de que de facto es inmenso el número de laudos que jamás tienen control judicial. Sin embargo, no veo allí una contradicción conceptual. Las partes de un acuerdo arbitral, como regla general, pueden renunciar a cualquier forma de control que recaiga sobre el laudo, una vez que lo conocen y, por lo tanto, entienden y conocen el alcance de la renuncia que formulan. Lo que no parece aceptarse hoy en día es que ello se haga a priori, pues esto implicaría una renuncia anticipada y hecha a ciegas respecto de un control que se ejerce sobre elementos fundamentales del arbitraje $y$, por lo tanto, podría permitir que un laudo que se dictara en franca contradicción con lo estipulado por las partes en el acuerdo arbitral, fuera definitivo sin que se ejerciera sobre él control alguno. Por esa razón, esta fórmula parece sensata y no sería conveniente avanzar hacia la expedición de laudos sin control alguno. 
